\title{
The Influence of the RMB Exchange Rate on the Export Trade in Jiangxi Province (China)
}

\section{Wang Fen}

School of Economics, Shanghai University, Shanghai, China

\section{Email address:}

18616786829@163.com

\section{To cite this article:}

Wang Fen. The Influence of the RMB Exchange Rate on the Export Trade in Jiangxi Province (China). Science Innovation.

Vol. 4, No. 4, 2016, pp. 186-189. doi: 10.11648/j.si.20160404.13

Received: July 6, 2016; Accepted: August 18, 2016; Published: August 21, 2016

\begin{abstract}
Since China's exchange rate regime reformed, the appreciation of the RMB has continued which will have an influence on the export trade of Jiangxi province. This paper aims to analyze the influence of fluctuations in exchange on the export trade of Jiangxi province, using the annual data of exports and GDP in Jiangxi province and the RMB exchange rate from 1994 to 2014 by the mothods of stationarity, cointegration and Granger causality test. And the result shows that with the appreciation of the RMB, the exports of Jiangxi province will increase.
\end{abstract}

Keywords: RMB Exchange Rate, Export Trade, Jiangxi Province

\section{人民币汇率对江西省出口贸易的影响}

\section{王芬}

经济学院, 上海大学, 上海, 中国

\section{邮箱}

18616786829@163. com

摘要: 自从中国进行汇率制度改革以来, 人民币就持续升值, 而人民币的持续升值将会对江西省的出口贸易产生影响, 本文旨在采用1994至2014年的人民币汇率、江西省出口额以及江西省生产总值的年度数据，通过平稳性检验、协整检 验以及格兰杰因果检验的方法, 来分析汇率变动对江西省出口贸易的影响, 研究结果表明人民币升值, 江西省出口额 会增加。

关键词：人民币汇率，出口贸易，江西省

\section{1. 引言}

在多元化的现代国际经济环境中, 汇率作为一种重要 的经济杜杆, 不仅关乎一国国内外部经济稳定和发展等重 大问题, 还对一省的经济稳定与发展有着重要影响。从 1979年开始, 中国对人民币汇率制度做了多次改革, 直到 2005年的7月 21 号, 我国确定实行新的汇率制度, 即以市 场供求为基础的、参考一篮子货币进行调节的、有管理的
浮动汇率制度, 希望通过汇率制度能够协调经济, 最大程 度上的促进我国经济的发展。但是自从实行新的汇率制度 以来，人民币汇率中间价由 $1: 8.11$ 变动为 2014 年的 $1: 6.14$, 涨幅累计高达 $32.08 \%$ 。汇率变动对中国的经济贸易产生了 影响, 也影响了江西省的出口贸易。

从2005年以来, 江西省的经济发展速度不断加快, 2015年江西省的生产总值为 16723.8 亿元, 按照可比价格 计算, 比2014年增长了9.1\%, 增速是全国的第五位、中部 
地区的第一名; 2015年江西省的外贸进出口总额为 2641.5 亿元, 比上年增长了 $0.7 \%$; 其中出口额为 2060.9 亿元, 较 上年增长了 $4.8 \%$, 这说明出口贸易是江西省经济发展迅速 的重要力量。所以在人民币不断升值的情况, 江西省的出 口贸易不可避免地会受其影响, 而我国又是一个区域发展 极其不平衡的大国, 在此背景下, 研究人民币汇率变动对 江西省出口贸易影响具有重要意义。

\section{2. 文献综述}

通过中国和中国以外国家众多专家学者的研究, 目前 关于汇率对进出口贸易的影响, 大致分为三种情况, 一种 是汇率变动会对外贸产生正向的影响; 另一种相反, 认为 汇率变动对外贸的影响是负向的; 还一种认为汇率变动对 外贸的影响不显著。

Eleanor Doyle (2001) 分析了汇率变动对爱尔兰主要 贸易对象的出口影响, 通过采用经济模型来进行实证分析, 研究表明名义或者真实汇率对爱尔兰的出口贸易的影响 是有利的 [1]。汤作华、侯俊华 (2015) 通过实证分析, 并根据实际数据来看, 人民币升值与江西出口贸易之间是 正向相关的, 人民币升值后, 江西的出口也持续地上涨了 [2]。王明涛（2015）通过1994-2013年的年度数据分析， 表明人民币升值没有一直广西的出口，而且随着人民币的 不断升值, 广西的出口额反而呈现出强劲增长的趋势 [3]。 王春平、刘传哲（2007）通过研究，表明人民币实际有效 汇率的变动对山东出口贸易具有正向影响, 人民币升值会 促进山东出口贸易的增长 [4]。周志红、陈雁云（2008） 通过计量分析, 认为人民币实际有效汇率和名义有效汇率 对江西出口的影响是一致的, 即有效汇率升值会使进口增 加, 出口减少 [5]。黄敏、尹亚红 (2007) 研究认为, 由 于江西省本身特殊的出口贸易结构, 使人民币升值能促进 江西出口商品的增加 [6]。邓水兰、温诒忠（2009）通过 研究表明, 人民币升值对江西省出口量的影响比较小 [7]。 房连伟 (2012) 分析得出汇率的变化对不同的产品有不同 的影响, 但总体来说, 人民币升值有利于江西省外贸总额 的增加, 但不是其主要影响因素 [8]。袁汝坤研究表明人 民币升值短期内对江西省出口的冲击作用有限, 长期内会 是江西省出口额的涨幅减少 [9]。王春平、刘传哲研究认 为人民币升值并不会对山东出口贸易产生负面的影响, 反 而会促进山东出口贸易额的增加 $[10]$ 。

\section{3. 模型构建}

\section{1. 数据选取}

由于1994年之前我国实行的是双轨制，1994年以后才 开始实行单一的、有管理的浮动汇率制度, 如果采用 1994 年以前的数据, 会使我国汇率的偏离程度会比较大, 所以 1994年之前的数据不能很真实的反映人民币汇率对江西 省出口贸易额的影响, 因此本文选取的是在直接标价法下, 1994年至2014年的人民币对美元汇率 (年平均价) 的年度 数据, 但是只考虑平均这一个因素的话, 是不够的。为此, 我们加入江西省历年GDP的值, 因为GDP的大小会影响出口
的供给能力, 也是影响江西出口的一个重要因素, 相应地, GDP和出口额的数据都采用年度数据, 具体数据如表 1 所示:

表1 江西省历年出口额和人民币汇率变动情况表。

\begin{tabular}{llll}
\hline 年份 & EXM & NER & GDP \\
\hline 1994 & 69.01 & 8.62 & 948.16 \\
1995 & 84.52 & 8.35 & 1169.73 \\
1996 & 70.92 & 8.31 & 1409.74 \\
1997 & 92.41 & 8.29 & 1605.77 \\
1998 & 84.42 & 8.28 & 1719.87 \\
1999 & 75.03 & 8.28 & 1853.65 \\
2000 & 99.14 & 8.28 & 2003.07 \\
2001 & 86.03 & 8.28 & 2175.68 \\
2002 & 87.10 & 8.28 & 2450.48 \\
2003 & 124.64 & 8.28 & 2807.41 \\
2004 & 165.15 & 8.28 & 3456.7 \\
2005 & 200.59 & 8.19 & 4056.76 \\
2006 & 300.07 & 7.97 & 4820.53 \\
2007 & 416.87 & 7.60 & 5800.25 \\
2008 & 541.30 & 6.95 & 6971.05 \\
2009 & 503.32 & 6.83 & 7655.18 \\
2010 & 907.98 & 6.77 & 9451.26 \\
2011 & 1416.10 & 6.46 & 11702.82 \\
2012 & 1584.65 & 6.31 & 12948.88 \\
2013 & 1752.54 & 6.19 & 14410.19 \\
2014 & 1966.65 & 6.14 & 15714.63 \\
\hline
\end{tabular}

数据来源: 国家统计局、江西统计年鉴 2015

\section{2. 数据来源与处理}

为了避免选用的模型出现异方差的问题, 因此在进行 建模前, 本文对自变量人民币对美元汇率 (NER)、江西省 GDP以及因变量江西省出口贸易额（EXM）的数据进行取对 数处理, 其中 1 exm表示江西省出口额的对数值、1ner表示 人民币兑美元汇率的中间价的对数值、 $1 \mathrm{gdp}$ 则表示的是江 西省GDP取对数后的数值。

表1中江西省出口额（EXM）和江西省GDP的值自1994 至2014年的年度数据来源于江西省统计年鉴 2015 ; 而人民 币汇率 (NER) 数据来源于国家统计局。

\section{3. 模型设定}

根据以上数据和处理结果, 本文将通过时间序列来研 究人民币汇率对江西省出口贸易的影响, 并以 lexm作为因 变量, 以 $1 \mathrm{gdp}$ 和 1 ner为自变量, 初步建立取对数后的实证 模型表达式如下:

$$
\operatorname{lexm}=c+\alpha \ln e r+\beta \lg d p+\mu
$$

\section{4. 实证分析}

\section{1. 平稳性检验}

本文所用的所有变量都属于时间序列变量, 而时间序 列变量大部分都存在时间趋势, 通常是不平稳的, 如果对 不平稳的时间序列变量进行回归分析, 产生 “伪回归” 的 
现象的可能性比较大, 从而导致最后得到错误的结论, 因 此我们有必要对所有的时间序列变量进行单位根的平稳 性检验, 平稳后才方便确定各变量之间是否存在协整关系, 即长期均衡关系。

本文通过Eviews 8.0 对模型进行ADF检验, 结果如下 表:

表2 所有变量单位根检验结果。

\begin{tabular}{llllll}
\hline \multirow{2}{*}{ 变量 } & ADF检验统计值 & \multicolumn{2}{l}{ 各显著性水平下的临界值 } & \multicolumn{2}{l}{ 检验结果 } \\
\hline lexm & -1.725664 & -4.498307 & -3.658446 & -3.268973 & 不平稳 \\
$\triangle 1$ exm & -4.004322 & -3.831511 & -3.029970 & -2.655194 & 平稳 \\
1 ner & -0.938083 & -4.498307 & -3.658446 & -3.268973 & 不平稳 \\
$\triangle 1$ ner & -2.166659 & -2.692358 & -1.960171 & -1.607051 & 平稳 \\
1 gdp & -1.483847 & -3.92035 & -3.065585 & -2.673459 & 不平稳 \\
$\triangle 1$ gdp & -2.962205 & -3.831511 & -2.92997 & -2.655194 & 平稳 \\
\hline
\end{tabular}

注: 表 2 中的 $\triangle$ 表示的变量的一阶差分

根据表2结果显示, 变量 1 exm、1ner和 $1 \mathrm{gdp}$ 的统计值 分别 $-1.725664 、-0.938083 、-1.483847$, 无论是在 $1 \%$ 还 是 $5 \%$ 亦或是 $10 \%$ 的置信水平下, 统计值都大于各置信水平 下的临界值, 不能拒绝原假设, 因此可以判断lexm、1ner 和 $1 \mathrm{gdp}$ 三个序列都是不平稳的。为此我们对原序列进行一 阶差分, 根据表 2 可知, 一阶差分后各序列平稳, 因此此 序列是一阶单整序列。

\section{2. EG两步法协整检验}

通过上述平稳检验, 可知本文的时间序列是一阶单整 的, 因此可以进行协整检验来验证各个变量之间是否存在 长期均衡关系。为此我们先通过最小二乘法 (OLS) 对序 列进行回归, 得到三者之间的回归方程为:

$$
1 \text { exm }=8.79-4.671 \text { ner }+0.75 g d p
$$

这说明人民币对美元汇率每减少一个百分点, 即人民 币升值, 江西省出口额就增加4.67个百分点; 江西省GDP 每增加一个百分点, 江西省出口额增加 0.75 个百分点。 然后将回归得到的残差序列et, 通过EG两步法对残差 序列进行单位根检验, 来观察残差序列是否平稳, 检验结 果如下:

表3 各变量ADF单位根检验结果。

\begin{tabular}{llllll}
\hline \multirow{2}{*}{ 变量 } & \multirow{2}{*}{$\begin{array}{l}\text { ADF 检验统 } \\
\text { 计值 }\end{array}$} & \multicolumn{3}{c}{ 各显著性水平下的临界值 } & 检 验 \\
\cline { 3 - 5 } & $1 \%$ & $5 \%$ & $10 \%$ & 结果 \\
\hline et & -4.376695 & -2.708094 & -1.962813 & -1.6060129 & 平稳 \\
\hline
\end{tabular}

由表 3 的检验结果可知, 残差序列et在 $1 \%$ 的置信水平 下, 统计值为-4. 376695, 小于临界值-2.708094, 因此可 以拒绝原假设, 即残差序列不存在单位根, 是平稳的, 这 也就说明人民币汇率、江西省GDP与江西省出口贸易额之 间是协整的，三者之间存在长期均衡关系。

\section{3. 格兰杰因果检验}

综上所述, 我们已经知道江西省出口贸易额与江西省 GDP和人民币汇率三者的一阶差分序列是平稳的, 并且这 三者在长期内存在稳定均衡的关系, 为了进一步说明 “谁 引起谁变化”, 我们通过Eviews 8.0 对相关数据进行 Granger因果检验, 检验中最优的滞后长度是通过构建VAR 模型以及 “SC准则” 确定为 3 , 以下为检验结果:

表4 Granger 因果检验结果。

\begin{tabular}{llll}
\hline Null Hypothesis: & Obs & F-Statistic & Prob. \\
\hline LNER does not Granger Cause LEXM & 18 & 2.76953 & 0.0918 \\
LEXM does not Granger Cause LNER & & 4.49617 & 0.0272 \\
LGDP does not Granger Cause LEXM & 18 & 6.23791 & 0.0099 \\
LEXM does not Granger Cause LGDP & & 3.15043 & 0.0686 \\
\hline
\end{tabular}

由表 4 可知, 在 $10 \%$ 的置信水平下, 各栏的P值分别为 0.0918、0.0272、0.0099以及 0.0686 , 都小于 0.1 , 因此 在 $10 \%$ 的置信水平下, 我们可以判断江西省GDP和人民币汇 率是江西省出口贸易额的格兰杰原因, 江西省出口贸易额 也是人民币汇率和江西省GDP的格兰杰原因, 这说明人民 币汇率和江西省GDP与江西省出口贸易会互相影响。

\section{5. 结论和建议}

\section{1. 结论}

通过实证分析结果显示, 人民币汇率与江西省出口贸 易额互为格兰杰原因, 并且人民币升值并没有给江西出口 贸易带来不利影响, 反而促进了江西出口贸易额的增加, 
我们会发现这与货币对外升值会不利于该国商品出口, 出 口会下降的传统经济学理论相反, 这是因为从短期来看, 是因为时滞效应的存在，即使人民币升值，但是升值之前 已经签订的出口贸易合同, 还是得按照合同内容中约定的 外币计价继续执行。

另一方面, 从长期来看, 这与江西省的出口贸易结构 有关, 江西出口的主要产品是纺织类和机电、家电类等劳 动力密集型产品, 这些产品的出口需求弹性小, 受人民币 升值的不利影响小。另外, 从贸易方式看, 江西省的出口 贸易主要是加工贸易, 在人民币升值的情况下, 江西省的 加工贸易中的进料加工, 使用的是大量的进口原材料或者 半成品, 人民币升值这些进口原材料价格会下降, 商品的 生产成本下降, 最终会扩大出口; 而加工贸易中来料加工 几乎不受人民币升值的影响。所以人民币升值是有可能 使江西省出口贸易额扩大的。除此之外, 在经济全球化、 产业分工全球化的今天, 汇率并不是影响出口的唯一因素, 而且人民币升值会使得同样人民币货值的商品能换得更 多的美元，这也会导致人民币升值时，出口额增加。

\section{2. 建议}

江西省作为一个农业大省, 出口的产品本来在国际市 场上竞争力比较低, 而且主要依赖于低廉的劳动力, 这些 产品的附加值和技术含量比较低, 而产品在国际市场上出 口, 依赖的是生产技术和创新能力。

所以江西省在复杂多变的国际大环境中, 江西省的政 府部门一方面应该加大出口退税政策的宣传, 并且积极引 导本省出口企业充分利用国家政策, 通过有利的国家政策 促进江西省出口产品结构的优化升级, 另一方面政府应该 多多鼓励本省企业加强品牌研发和创造意识、多加开发本 省自主品牌, 通过政府机关和企业自身的宣传和推广, 打 出一片新天地。

其次, 从出口企业自身来说, 应该努力提高自身的汇 率风险的抵抗能力, 在对外出口时, 企业可以一些金融工 具, 比如人民币远期外汇、外汇期货期权以及外汇互换等, 还可以通过订立合同，尽量要求使用硬币收款，使用软币 支付货款来避免或减少汇率风险。
最后，企业应该加大对生产技术能力的提高，通过招 收省内外优秀的技术人员, 加强基础技术设施建设, 以及 通过一些技术培训和交流互动, 来提升生产技术, 从而提 高本企业的产品附加值, 以此来提高出口企业的竞争力, 从而在国际市场上扩大本省商品的出口力, 更好地占领国 际市场。

\section{参考文献}

[1] Eleanor Doyle. Exchange Rate Volatility and Irish-UK trade [J]. Applied Economics, 2001, (2) : 249-266

［2］汤作华、侯俊华.人民币汇率波动、FDI转移对江西省贸易 出口影响的实证研究 [J]. 科技广场, 2015, (1) : 209-210

［3］王明涛.人民币汇率对广西出口贸易的影响-基于 1993-2013年年度数据的实证分析 $[J]$. 广西财经院报, 2015, 28, (6) : 53-54

４4］王春平、刘传哲. 人民币实际有效汇率变动对山东出口贸易 的影响 [J]. 山东社会科学, 2007, (2) : 104-105

[5] 周志红、陈雁云. 有效汇率变动对江西进出口影响的计量分 析 [J]. 科技经济市场, 2008, (9) : 55-56

［6］黄敏、尹亚红. 人民币汇率变动对江西出口贸易影响的实证 分析 $[J]$.生产力研究, 2007, (16) : 84

[7] 邓水兰、温诒忠. 汇率变动对江西出口贸易影响分析 [J]. 价格月刊, 2009, (4) : 46

［8］房连伟、万树平. 二次汇改后人民币汇率变动对江西外贸影 响的实证分析 [D]. 江西: 江西财经大学, 2012: 34-57

［9］袁汝坤、彭玉镏. 人民币汇率变动对江西省经济增长影响的 实证分析 [D]. 江西: 江西财经大学; 2014，24-44

[10］王春平、刘传哲. 人民币实际有效汇率变动对山东出口贸易 的影响 [J]. 山东社会科学, 2007, (2) : 105-105 